\title{
Comparison among three methods for mycobacteria identification
}

\author{
Misael Mondragón-Barreto, Q.F.B., (1) Carlos A.Vázquez-Chacón, Q.F.B.,(1) \\ Candelaria Barrón-Rivero, Q.B.P., (1) Patricia Acosta-Blanco, Q.B.P., (1) Kenneth C. Jost Jr, B.A.M. (A.S.C.P.), ${ }^{(2)}$ \\ Susana Balandrano, Biól.., ${ }^{(1)}$ Hiram Olivera-Díaz, M. en I.B.B. ${ }^{(1)}$
}

\begin{abstract}
Mondragón-Barreto M, Vázquez-Chacón CA, Barrón-Rivero C, Acosta-Blanco P, Jost KC Jr, Balandrano S, Olivera-Díaz H. Comparison among three methods for mycobacteria identification. Salud Publica Mex 2000;42:484-489.
\end{abstract}

\begin{abstract}
Objective. To compare three methods: Biochemical tests, high-performance liquid chromatography (HPLC) and polymerase chain reaction-restriction fragments length polymorphism (PCR-RFLP), for the identification of mycobacteria, and to perform a cost-benefit analysis to define an optimum identification algorithm. Material and methods. One-hundred-and-seven mycobacteria isolates were identified by the three methods at Instituto de Diagnóstico y Referencia Epidemiológicos, between February of 1999 and January of 2000 and the results were compared with those of a reference laboratory using the Q-Cochran statistical test. Results. PCR-RFLP was the most rapid and specific procedure but also the most expensive; biochemical tests excelled for identification of Mycobacterium tuberculosis, but were lengthy and expensive for other mycobacteria; HPLC ranked in the middle for price, speed and specificity. Conclusions. Considering the expected proportion of M. tuberculosis, the following algorithm was proposed: Initially, biochemical tests should be performed; if the results indicate a non-tuberculous mycobacteria, the isolate should be analyzed with HPLC; if results are unclear, the isolate should be analyzed using PCR-RFLP. Isolates showing a previously undescribed PCR-RFLP pattern should be characterized by DNA sequencing.
\end{abstract}

Key words: Mycobacterium/diagnosis; diagnosis, laboratory; chromatography, high-performance liquid/diagnostic use; Mexico

\author{
Mondragón-Barreto M, Vázquez-Chacón CA, \\ Barrón-Rivero C, Acosta-Blanco P, Jost KC Jr, \\ Balandrano S, Olivera-Díaz H. \\ Comparación entre tres métodos \\ para identificar micobacterias. \\ Salud Publica Mex 2000;42:484-489.
}

\section{Resumen}

Objetivo. Comparar tres métodos: pruebas bioquímicas, cromatografía líquida de alta resolución (HPLC, por sus siglas en inglés) y reacción en cadena de la polimerasa-polimorfismo del tamaño de fragmentos de restricción (PCR-RFLP) para identificar micobacterias a nivel especie, analizando costo-beneficio y proponiendo un algoritmo de identificación. Material y métodos. Entre febrero de 1999 y enero de 2000, en los laboratorios del Instituto de Diagnóstico y Referencia Epidemiológicos se tipificaron 107 aislados de micobacterias y los resultados se compararon con los obtenidos en un laboratorio de referencia utilizando la prueba estadística $\mathrm{Q}$ de Cochran. Resultados. Se encontró que el PCR-RFLP fue el método más específico y rápido pero también el más caro. Las pruebas bioquímicas fueron confiables para la identificación de Mycobacterium tuberculosis, pero lentas e inespecíficas para otras micobacterias. El HPLC estuvo en un nivel medio tomando en cuenta costo, tiempo y especificidad. Conclusiones. Considerando la proporción esperada de $M$. tuberculosis, se propone el siguiente algoritmo: si las pruebas bioquímicas indican una micobacteria no tuberculosa, el aislado será analizado por HPLC; si la identificación no es clara, el aislado será analizado usando PCR-RFLP. Si el aislado no pertenece a un patrón descrito, se identificará por secuenciación de ADN.

Palabras clave: Mycobacterium/diagnóstico; diagnóstico de laboratorio; cromatografía líquida de alta resolución/uso diagnóstico; México

(I) Departamento de Biología Molecular y Departamento de Micobacterias, Instituto de Diagnóstico y Referencia Epidemiológicos. México, D.F., México.

(2) Mycobacteriology/Mycology Branch, Bureau of Laboratories, Texas Department of Health. Austin, Texas, United States of America. 
$\mathrm{T}$ he diseases produced by species of the genus $M y$ cobacterium are important causes of morbidity and mortality in the world; they have increased due to HIV infections, with the involvement mainly of $M$. tuberculosis and M. avium complexes. ${ }^{1}$ The identification of mycobacteria to the species level is important because of the clinical significance; some species are pathogenic while others are not. Knowledge of species is also critical in order to provide adequate patient management because specific antimycobacterial drugs are required against different pathogenic mycobacteria species. ${ }^{2}$

The conventional methods for the identification of mycobacteria, currently used at Instituto de Diagnóstico y Referencia Epidemiológicos (InDRE) in Mexico City, are based on culture and biochemical tests, they require several weeks for adequate growth, and sometimes, accurate identification is not possible. ${ }^{3}$ Difficulties such as lack of adequate reproducibility, the variability of phenotypes, and the fact that phenotype information is limited to common species, may lead to ambiguous or erroneous results. ${ }^{2}$ Alternative techniques have been established, such as thinlayer chromatography, gas-liquid chromatography, high-performance liquid chromatography (HPLC), and molecular techniques based on hybridization, amplification, or sequencing of nucleic acids, but in developing countries they are generally limited to research laboratories. ${ }^{3}$

This study was designed to compare (from economic and operational points of view), mycobacteria biochemical tests with two new techniques, HPLC and PCR: HPLC separates mycolic acids extracted from bacterial cell wall, that are derivatized to their p-bromophenacyl esters as a function of their chain length, unsaturated acids, and functional groups, thus generating a distinctive pattern for each species of mycobacteria. ${ }^{4,5}$ The polymerase chain reaction (PCR)-based method amplifies a fragment of the gene that codes for the 65-KDa heat-shock protein (hsp65), followed by restriction fragments length polymorphism (RFLP) analysis, using the restriction enzymes HaeIII and BstEII. 3,6

The objective of the study was to implement a new algorithm for processing mycobacterial strains that arrive at this Institute, to offer a more efficient service.

\section{Material and methods}

This was a masked study, conducted between February 1999 and January 2000 at Instituto de Diagnóstico y Referencia Epidemiológicos in Mexico City. A total of 107 isolates were analyzed, 76 of which had been previously identified as non-tuberculous mycobacteria, and 31 as $M$. tuberculosis complex isolates.

Sample size was calculated for a confidence interval of $95 \%(p<0.05)$. Strains were selected and analyzed in a double-masked fashion. Four subcultures for each strain were obtained independently to perform biochemical tests, HPLC, PCR-RFLP, and one external control test (Texas Department of Health, Austin TX, USA); the identification algorithm consisted firstly of HPLC and then, if any strain was difficult to identify, genetic probes and biochemical tests were used.

Ultraviolet-detection HPLC was performed as described by the U.S. Department of Health and Human Services. ${ }^{7}$ A newer reference version that has now been published, ${ }^{8}$ was not available when this study was conducted.

For PCR-RFLP, DNA was extracted as described by van Soolingen..$^{9}$ Basically, bacterial cells were lysed with lysozyme, proteinase $\mathrm{K}$ and SDS, followed by $\mathrm{CTAB} / \mathrm{NaCl}$ and chloroform extraction; DNA was then precipitated with isopropanol, washed twice with ethanol, and resuspended in $20 \mu \mathrm{l}$ of sterile distilled water. The PCR procedure was partially based on Telenti et al. ${ }^{6}$ Primers Tb11 (5'-ACC AAC GAT GGT GTG TCC AT) and Tb12 (5' -CTT GTC GAA CCG CAT ACC CT) were used to amplify a 439-bp fragment of the hsp65 gene; reaction conditions included a pre-incubation time of 2 min at $94{ }^{\circ} \mathrm{C}$, followed by 40 two-step cycles of $30 \mathrm{sec}$ at $94{ }^{\circ} \mathrm{C}$, and $2 \mathrm{~min}$ at $67^{\circ} \mathrm{C}$. PCR products were electrophoresed in $2 \%$ agarose gels and digested separately by restriction endonucleases BstEII and HaeIII. Restriction products were analyzed on $12 \%$ polyacrilamide gels using pBR322/HaeIII as the molecular weight standard. Restriction patterns were compared with the algorithm reported by Devallois et al. ${ }^{3}$

Biochemical analysis began by determining growth rate and pigment production for each isolate. To find the optimal temperature for growth, each strain was incubated at several temperatures $(25,37$, and $42{ }^{\circ} \mathrm{C}$ ). Three biochemical tests; niacin, nitrate reduction, and catalase production at $68^{\circ} \mathrm{C}$, were performed. Niacin and nitrate-positive isolates and $68^{\circ} \mathrm{C}$ catalasenegative isolates were reported as $M$. tuberculosis. Niacin-negative, $68{ }^{\circ} \mathrm{C}$ catalase-positive and/ or nitrate-negative isolates were further characterized with other biochemical tests like iron uptake, $5 \% \mathrm{NaCl}$ tolerance, Tween hydrolysis, $1 \mathrm{mM}$ and $3 \mathrm{mM}$ aryl sulfatase, potassium tellurite reduction, and urease. ${ }^{10-12}$

Result data were entered into a database, to calculate the sensitivity for each method, and concordance percentages between methods and with the reference laboratory. Finally, a time and resources analysis was 
made for each method. Statistical analysis was performed using the WinstatTM statistical package; QCochran's test was used to obtain $p$ values of $p<0.05$, $p<0.01$ and $p<0.001$.

\section{Results}

One-hundred-and-seven Mycobacterium isolates from our institutional collection were identified to the species level. Thirty-one belonged to the M. tuberculosis complex and the remaining were non-tuberculous mycobacteria.

The fastest method was the PCR-RFLP; results from HPLC and biochemical testing required 5 and 15 additional days, respectively. The differences were mainly due to the larger amount of cells required for ultraviolet-detection HPLC and to the large number of biochemical tests necessary for the identification of non-tuberculous mycobacteria.

Identification results with the three methods compared with the reference laboratory are summarized in Table I. Basically, for the identification of M. tuberculosis complex, the three methods were adequate. PCRRFLP was more sensitive, since it correctly identified all $31 \mathrm{M}$. tuberculosis isolates; HPLC identified 28 isolates, and the biochemical tests identified 26. For the non-tuberculous mycobacteria, PCR-RFLP was also more sensitive; especially remarkable was that this technique identified 20 from $24 \mathrm{M}$. avium complex isolates, while the HPLC and the biochemical tests only identified 18 and 5 isolates, respectively. This was partially due to the observation of 6 unusual HPLC patterns (Table II) and 19 pigmented isolates that also showed an altered growth rate.

Specificity was calculated for each species, considering as negatives all the isolates not belonging to that particular species and as false negatives, the isolates erroneously identified as belonging to the species.

For M. tuberculosis the specificity was $98.7 \%$ for two methods, PCR-RFLP and biochemical tests, with only one error in 76 samples. HPLC specificity was initially only $83.1 \%$ because $M$. terrae and $M$. avium complexes isolates showed different patterns from those found in the CDC manual, ${ }^{7}$ and only a limited number of $M$. terrae complex reference patterns were available at our Institute at the time of the study. Additional $M$. terrae and $M$. avium complexes reference patterns were obtained and compared with the isolates that were mistakenly identified as $M$. tuberculosis. It was then possible to clearly differentiate all of $M$. terrae and M. avium complexes isolates from $M$. tubercu-
Table I

Sensitivity of the three Methods for SPECIES IDENTIFICATION COMPARED WITH THE REFERENCE LABORATORY

Species

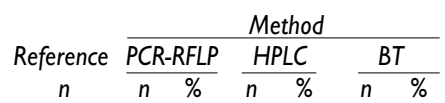

Mycobacterium tuberculosis

\begin{tabular}{lrrrrrrr}
\hline complex & 31 & 31 & 100 & 28 & 90 & $26 *$ & 84 \\
\hline Mycobacterium fortuitum & 19 & 18 & 95 & 17 & 90 & $13 *$ & 68 \\
\hline Mycobacterium avium complex & 24 & $20 *$ & 83 & $18 *$ & 75 & $5 \S$ & 21 \\
\hline Mycobacterium gordonae & 14 & 11 & 79 & $6 \neq$ & 43 & $8^{*}$ & 57 \\
\hline Mycobacterium terrae complex & 10 & 3 & 30 & 0 & 0 & 3 & 30 \\
\hline Mycobacterium simiae & 5 & 5 & 100 & 3 & 60 & 0 & 0 \\
\hline Mycobacterium flavescens & 2 & 0 & 0 & 0 & 0 & 1 & 50 \\
\hline Mycobacterium asiaticum & $\mathrm{I}$ & $\mathrm{I}$ & 100 & $\mathrm{I}$ & 100 & 0 & 0 \\
\hline Mycobacterium marinum & $\mathrm{I}$ & $\mathrm{I}$ & 100 & 0 & 100 & 0 & 0
\end{tabular}

Q-Cochran test, ${ }^{*} p<0.05,{ }^{\ddagger} p<0.01,{ }^{\S} p<0.00$ I

Table II

Number AND PERCENTAGE OF STRAINS WITH ATYPICAL PATTERNS

\begin{tabular}{|c|c|c|c|c|c|c|c|}
\hline \multirow{2}{*}{ Species } & \multirow{2}{*}{$\begin{array}{c}\text { Refernce } \\
n\end{array}$} & \multicolumn{2}{|c|}{ PCR-RFLP } & \multicolumn{2}{|c|}{ HPLC } & \multicolumn{2}{|c|}{ BT } \\
\hline & & $n$ & $\%$ & $n$ & $\%$ & $n$ & $\%$ \\
\hline \multicolumn{8}{|l|}{ Mycobacterium tuberculosis } \\
\hline complex & 31 & 0 & 0 & 3 & 10 & 0 & 0 \\
\hline Mycobacterium avium complex & 24 & 0 & 0 & 6 & 38 & 19 & 80 \\
\hline Mycobacterium fortuitum & 19 & 0 & 0 & 2 & II & 6 & 32 \\
\hline Mycobacterium gordonae & 14 & 3 & 21 & 8 & 62 & 6 & 43 \\
\hline lycobacteriur & 10 & 7 & 70 & & 100 & & 70 \\
\hline
\end{tabular}

losis. After correcting for these isolates, specificity of HPLC was $100 \%$.

Statistical analysis showed significant differences $(p<0.05)$ among the three tests for the identification of $M$. tuberculosis and M. avium complexes, but not for $M$. fortuitum and M. gordonae. Statistical significance and differences between each test and the reference test are shown in Table I.

Cost analysis of the three methods is shown in Table III. In this analysis we separated the biochemical procedures for $M$. tuberculosis from those required for the identification of non-tuberculous mycobacteria. The least expensive method for M. tuberculosis identification was the biochemical test; it was also the fastest, since it required only one day. For non-tuberculous 
Table III

RESOURCES CONSUMED FOR EACH IDENTIFICATION METHOD OF MYCOBACTERIA TO SPECIES LEVEL

\begin{tabular}{|c|c|c|c|c|c|c|c|}
\hline Method & $\begin{array}{l}\text { Time } \\
\text { (days) }\end{array}$ & Workers & Samples per day & $\begin{array}{c}\text { Salary per sample } \\
\text { (USD) }\end{array}$ & $\begin{array}{l}\text { Reagents } \\
\text { (USD) }\end{array}$ & $\begin{array}{l}\text { Material } \\
\text { (USD) }\end{array}$ & $\begin{array}{l}\text { Cost per sample } \\
\text { (USD) }\end{array}$ \\
\hline BT (M. tuberculosis) & I & I & 20 & 1.7 & 1.3 & 1.0 & 4.0 \\
\hline BT (NTM) & $30-40$ & 2 & 20 & 3.4 & 3.05 & 3.65 & 10.1 \\
\hline HPLC & I & I & 5 & 6.8 & 3.7 & 2.3 & 12.8 \\
\hline PCR-RFLP & 2 & 2 & 20 & 3.4 & 3.6 & 5.9 & 13.0 \\
\hline \multicolumn{8}{|c|}{$\begin{array}{l}\text { BT: biochemical tests } \\
\text { NTM: non-tuberculous mycobacteria } \\
\text { HPLC: high performance liquid chromatography } \\
\text { PCR-RFLP: polymerase chain reaction-restriction }\end{array}$} \\
\hline
\end{tabular}

mycobacteria, biochemical tests were inefficient, costly, and required more than 30-40 days. HPLC was as fast as the biochemical tests for $M$. tuberculosis identification, with the advantage that it can identify other mycobacteria at the same time, but at a higher price. Finally PCR-RFLP was the most expensive procedure, and required one more day than the other methods; but like HPLC, PCR-RFLP can also immediately identify non-tuberculous mycobacteria. Furthermore, it was also the most accurate method, as shown in Tables I and II.

\section{Discussion}

Results obtained in this work showed that the basic methodology for mycobacteria identification, including colonial morphology, pigmentation, growth rate, and enzymatic tests, was fast and reliable for the identification of $M$. tuberculosis isolates, requiring three tests performed in a single day from a well-grown homogeneous culture. However, a non-tuberculous mycobacteria strain implied a lengthy process that required up to nine different tests and took approximately 6 to 8 weeks. After finishing this long and time-consuming procedure, we often found that the results were not absolute, because sometimes intra-species variation in enzymatic activity and phenotypic characteristics were observed. In the present work, these variations made particularly difficult the identification of species belonging to the $M$. terrae and M. avium complexes. Wallace et $a l^{13}$ reported that $80 \%$ of $M$. avium complex strains recovered from patients with HIV show pigmentation. This feature was not considered for M. avium complex identification at our laboratory, leading to an erroneous assignation of species. Another source of uncertainty was the reported heterogeneity for $M$. terrae complex, that led to the low sensitivity observed for those isolates with the three methods. Interestingly, the three strains belonging to $M$. terrae complex identified by PCR-RFLP were $M$. nonchromogenicum, which has been shown to be pathogenic to humans. ${ }^{14,15}$

With the use of an adequate collection of reference patterns, identification by HPLC was reliable. The required time to obtain a result from a pure culture was 1 to 2 days. Nowadays, this technique is well standardized and we have now patterns allowing the identification of up to 20 species. ${ }^{8}$ In our study, HPLC took more time than PCR-RFLP, partially because there were too many strains to analyze simultaneously, but also because ultraviolet-based HPLC needs more cells than the PCR procedure and therefore more time was required to obtain the cell mass. Faster identification by HPLC could be possible by developing more sensitive fluorescence detection of mycolic acid esters. ${ }^{16}$

The problem with identification of $M$. avium and $M$. terrae complexes emphasized the need for adequate HPLC reference patterns.

The PCR-RFLP was the most precise of the three methods and at least as fast as the HPLC; moreover, it can identify up to 34 Mycobacterium species ${ }^{3}$ and can also identify several Nocardia and other aerobic actinomycetes. ${ }^{17,18}$ In fact, as described above, this method was the first to finish the identification of all the isolates, because it allows the technicians to process more isolates on a daily basis.

Another important aspect was the cost of the techniques. In a direct comparison, we found that the biochemical tests used for $M$. tuberculosis identification were the least expensive, followed by HPLC and biochemical tests for non-tuberculous mycobacteria, while PCR-RFLP was the most expensive. However, we also have to consider that a faster and more accurate identification of mycobacteria allows a faster recovery of the patients and important savings in drugs; since cur- 
rent tuberculosis treatment takes about 6 months, costs around \$100 USD in Mexico, and is useless when the infection is caused by non-tuberculous mycobacteria.

We think that more efficient identification of mycobacteria could be achieved by a combination of the three methods in an optimized algorithm (Figure 1), considering cost-benefit and time-saving criteria. This algorithm will be used at our Institute following the publication of this study: When the primary culture is obtained, the three basic biochemical tests to identify $M$. tuberculosis are performed. When these tests suggest a non-tuberculous mycobacteria, the isolate is then analyzed by HPLC, which allows the identification of most species at a relatively low cost. If an unusual HPLC pattern is found or there is not enough growth for a clear identification, the isolate is analyzed by PCRRFLP, which allows the identification of a wider variety of species with a smaller sample. When a sample with clinical or epidemiological characteristics suggesting non-tuberculous mycobacteria arrives at our Institute, the sample will be analyzed directly by PCRRFLP to obtain faster results. If the PCR-RFLP is unable to give an unequivocal result, sequencing of $16 \mathrm{~S}$ RNA and the $h s p 65$ gene will be performed for a final identification or for its inclusion in the data banks if new species are encountered. Finally, the importance of other methods like the hybridization tests used in the reference laboratory at the Texas Department of Health should be considered. These tests have the advantage of being highly specific, but the disadvantage that a specific test for each species is required. These tests are not recommended for the screening of a large

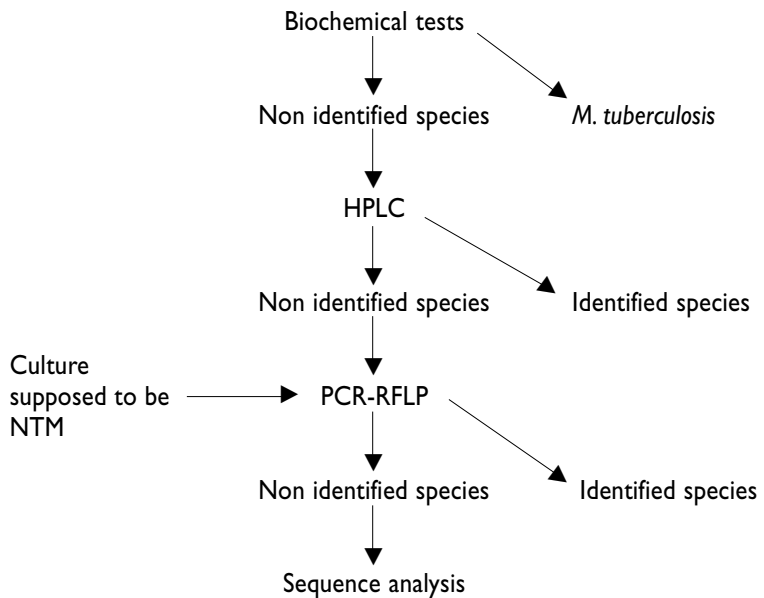

Figure I. Optimized algorithm for identification of MYCOBACTERIA TO THE SPECIES LEVEL number of unknown isolates, but are the best available to confirm an uncertain identification performed by other methods, or when the identification reaches a point from which only a limited number of species can be assigned.

\section{Acknowledgments}

We acknowledge Q.B.P. Lorena Chávez-González and Q.B.P. Ma. de Lourdes Olivares-Delgado for their technical assistance, Dr. Mayra García-Ruiz for advice in statistics and we are specially grateful to the InDRE's Research Workshop organized by Dr. Ma. Dolores Correa-Beltrán for encouragement, support and creative discussion. We also thank the staff of the Texas Department of Health Mycobacteriology/Mycology Laboratory, especially Sher H. Chiu, for their assistance with reference identification.

\section{References}

I. Plikaytis BB, Plikaytis BD, Yakrus MA, Butler WR, Woodley CL, Silcox VA et al. Differentiation of slowly growing Mycobacterium species, including Mycobacterium tuberculosis, by gene amplification and restriction fragment length polymorphism analysis. J Clin Microbiol 1992; 30:1815-1822.

2. Springer B, Stockman L, Teschner K, Roberts GD, Böttger EC. Twolaboratory collaborative study on identification of mycobacteria: Molecular versus phenotypic methods. J Clin Microbiol 1996; 34:296-303.

3. Devallois A, Goh KS, Rastogi N. Rapid identification of mycobacteria to species level by PCR-restriction fragment length polymorphism analysis of the hsp65 gene and proposition of an algorithm to differentiate 34 mycobacterial species. J Clin Microbiol 1997; 35:2969-2973.

4. Butler WR, Jost KC Jr, Kilburn JO. Identification of mycobacteria by high-performance liquid chromatography. J Clin Microbiol 1991;29: 2468-2472.

5. Butler WR, Thibert L, Kilburn JO. Identification of Mycobacterium avium complex strains and some similar species by high-performance liquid chromatography.J Clin Microbiol 1992; 30:2698- 2704.

6. Telenti A, Marchesi F, Balz M, Bally F, Böttger EC, Bodmer T. Rapid identification of mycobacteria to the species level by polymerase chain reaction and restriction enzyme analysis. J Clin Microbiol 1993; 31:175-178.

7. Butler WR, Cage G, Desmond E, Duffey PS, Floyd MM, Gross WM et al. Standardized method for the HPLC identification of mycobacteria. Atlanta (GA): Centers for Disease Control and Prevention, 1996.

8. Butler WR, Cage G, Desmond E, Duffey PS, Floyd MM, Gross WM et al. Mycolic acid pattern standards for HPLC identification of mycobacteria. Atlanta (GA): Centers for Disease Control and Prevention, 1999.

9. Van Soolingen D, Hermans PWM, de Hass PEW, Soll DR, van Embden JDA. Occurrence and stability of insertion sequences in Mycobacterium tuberculosis complex strains: Evaluation of an insertion sequence-dependent DNA polymorphism as a tool in the epidemiology of tuberculosis. J Clin Microbiol 1991;29:2578-2586.

10. Vestal AL. Procedures for the isolation and identification of mycobacteria. Atlanta (GA): Department of Health, Education, and Welfare, Public Health Service, CDC, 1975;42-95.

II. Kent PT, Kubica GP. Public health mycobacteriology: A guide for the level III laboratory. Atlanta (GA): Centers for Disease Control, US Department of Health and Public Services, 1985. 
12. Strong BE, Kubica GP. Isolation and identification of Mycobacterium tuberculosis: A guide for the level II laboratory. Atlanta (GA): Centers for Disease Control, US Department of Health and Public Services, I98I.

13. Wallace RJ Jr, O'Brien R, Glassroth J, Raleigh J, Dutt A. Diagnosis and treatment of disease caused by non-tuberculous mycobacteria. Am Rev Respir Dis 1990; 142:940-953.

14. Torkko P, Suutari M, Suomalainen S, Paulin L, Larsson L, Katila ML. Separation among species of Mycobacterium terrae complex by lipid analyses: Comparison with biochemical tests and I6S RNA sequencing.J Clin Microbiol 1998;36:499-505.

15. Ridderhof JC, Wallace RJ, Kilburn JO, Butler WR, Warren NG, Tsukamura $\mathrm{M}$ et al. Chronic tenosynovitis of the hand due to Mycobacterium nonchromogenicum: Use of high-performance liquid chromatography for identification of isolates. Rev Infect Dis 199|;13:857-864.
16. Jost KC Jr, Dunbar DF, Barth SS, Headley VL, Elliott LB. Identification of Mycobacterium tuberculosis and M. avium complex directly from smear-positive sputum specimens and BACTEC I2B cultures by high-performance liquid chromatography with fluorescence detection and computer-driven pattern recognition models. J Clin Microbiol 1995; 33:1270-1277.

17. Steingrube VA, Wilson RW, Brown BA, Jost KC Jr, Blacklock Z, Gibson $\mathrm{JL}$ et al. Rapid identification of clinically significant species and taxa of aerobic actinomycetes, including Actinomadura, Gordona, Nocardia, Rhodococcus, Streptomyces, and Tsukamurella isolates, by DNA amplification and endonuclease restriction analysis. J Clin Microbiol 1997;35:817-822.

18. Wilson RW, Steingrube V, Brown B, Blacklock Z, Jost KC Jr, McNabb A et al. Recognition of a Nocardia transvalensis complex by resistance to aminoglycosides, including amikacin and PCR-restriction fragment length analysis. J Clin Microbiol 1997;35:2235-2242. 